$\mathbb{P}$ periodica polytechnica

Civil Engineering

$51 / 1$ (2007) 9,15

doi: 10.3311/pp.ci.2007-1.02

web: http://www.pp.bme.hu/ci

(c) Periodica Polytechnica 2007

RESEARCH ARTICLE

\section{Optimal design of frame structures with semi-rigid joints}

Anikó Csébfalvi

Received 2006-04-03

\begin{abstract}
In this paper, a genetic algorithm is proposed for discrete minimal weight design of steel planar frames with semi-rigid beamto-column connections. The frame elements are constructed from a predetermined range of section profiles. Conventionally, the analysis of frame structures is based on the assumption that all connections are either frictionless pinned or fully rigid. Recent limit state specifications permit the concept of semi-rigid connection of the individual frame members in the structural design. In a frame with semi-rigid joints the loading will create both a bending moment and a relative rotation between the connected members. The moment and relative rotation are related through a constitutive law which depends on the joint properties. The effect, at the global analysis stage, of having semi-rigid joints instead of rigid or pinned joints will be that not only the displacements but also the distribution of the internal forces in the structure must be modified. In this study, a simplified beamto-column connection is presented which was specified in EC3 Annex J. In order to capture the changes in the nodal force and moment distribution in terms of joint flexibility, the ANSYS finite element analysis is applied. The structural model is formulated as a combination of $3 D$ quadratic beam elements and linear torsional springs. Present work deals with the effects of joint flexibility to the optimal design problem. The design variables including joint properties - are discrete. Results are presented for sway frames under different load conditions.
\end{abstract}

\section{Keywords}

discrete optimization $\cdot$ frames $\cdot$ semi-rigid $\cdot$ genetic algorithm

\section{Acknowledgement}

This work was supported by the Hungarian National Science Foundation No.T046822.

\section{Anikó Csébfalvi}

Department of Structural Engineering, University of Pécs, Pécs, Hungary e-mail: csebfalv@witch.pmmf.hu

\section{Introduction}

It is well known that real beam-to-column connections possess some stiffness, which falls between the extreme cases of fully rigid and ideally pinned. In the engineering practice, the traditional approaches to the design of frames are concisely described as continuous framing with rigid joints and/or simple framing with pinned joints. However, the connection behaviour significantly affects the displacements and internal force distribution of framed structures.

There is a large amount of work dealing with the effect of semi-rigid joints on the optimal design of frame structures. Fully analytical and numerical solutions as well have demonstrated that in actual framed structures, pinned connections possess a certain amount of stiffness, while rigid connections possess some degree of flexibility [1, 6, 7, 10, 11]. Recently, the European Code (EC 3) for design of steel structures [4,5] has adopted semi-rigid steel framing construction. The proposed approach to frame design, i.e. semi-continuous framing using semi-rigid joints, is then outlined; how it is to be distinguished from the traditional approaches is explained and the potential benefits (scientific and economic) for its use are raised.

It is now well recognized that assuming joints to be rigid or pinned may neither be accurate nor result be economical. Simply the fast that a joint has sufficient strength does not mean that it has sufficient stiffness to be reasonable to be modelled as rigid. Many joints, often assumed to be rigid exhibit an intermediate behaviour between the "rigid" and "pinned" states. Eurocode 3 Part 1-1 has taken this fact into account and in doing so opened the way to what is now known as "the semi-rigid approach".

In the semi-rigid approach, the behaviour of the joints is taken into account at the outset, i.e. when the components are sized at the preliminary design range, and the sizing takes account of the joint behaviour as well. The initial global analysis includes an approximate estimate of the joint characteristics (stiffness, strength and rotation capacity), and which can be refined later, as one does for the member sizes, in the final analysis. The joint is usually represented as a rotational spring at the extremity of the member (usually the beam) which characterizes the joint behaviour. Available models can represent the moment-rotation 
characteristic only, which is sufficient for the majority of structural joints in frames (see in EC3 Annex J.).

The aim of this study is to determine the effects of semirigid connection in optimal design of frame structures. The design variables are the member sections where column and beam members are distinguished. The properties of the connection spring will be changed as well during the process in a predetermined range of spring rotational stiffness.

In this study, a genetic algorithm method is applied for discrete minimal weight design of steel structures with semi-rigid connection.

Recently GA methods are very popular and have been used for sizing, shape, and topology optimization of structures. The GA methods are search algorithms that are based on the concepts of natural selection and natural genetics. The core characteristics of GAs are based on the principles of survival of the fittest and adaptation. The GA methods operate on population of set of design variables. Each design variable set defining a potential solution is called a string. Each string is made up of series of characters as binary numbers, representing the discrete variables for a particular solution. The fitness of each string is a measurement of performance of design variables defined by the objective function and constraints. GA methods consist of a series of three processes: coding and decoding design variables into strings, evaluating the fitness of each solution strings, and applying genetic operators to generate the next generation of solution strings. Most GA methods are variation of the simple GA proposed by Goldberg and Samtani [3], which consists of three basic genetic operators: reproduction, crossover, and mutation. By varying these parameters, the convergence of the problem may be altered. Much attention has been focused on finding the theoretical relationship among these parameters. Rajeev and $\mathrm{Kr}$ ishnamoorty [9] applied GA for optimal truss design and transmission tower. They presented all the computations for three successive generations. In a previous work of the first author [2] applied a GA for discrete minimal weight design problem of space trusses with plastic collapse constraints.

Hayalioglu and Degertekin [6] presented a genetic algorithm for optimum design of non-linear steel frames with semi-rigid connections subjected to displacement and stress constraints of AISC-ASD specifications. The authors [6] concluded that more economical frames can be obtained by adjusting the stiffness of the connections.

This study presents a discrete optimal design problem for steel frames with semi-rigid connection based on the recommendation of EC 3 while European cross sections are selected for frame members.

\section{The Discrete Optimization Problem}

Recently, several works have attended to optimal design of steel frames with semi-rigid connections. Here we will refer to some of the results e.g. papers of Hayalioglu and Degertekin [6], Jármai and Farkas [7], Xu and Grierson [10], and Xu [11].
The total cost is defined by $\mathrm{Xu}$ and Grierson that includes the structural cost and the connection cost as well. In this study, contrary to the papers mentioned above, the objective function will be the least weight of the structure because the total cost strongly depends on the actual price of raw materials and the actual cost of manufacturing.

\subsection{Semi-rigid Frame Analysis}

In general, there are two different ways to incorporate connection flexibility into computer-based frame analysis.

In this paper, the idea of $\mathrm{Xu} 12$ will be adopted where the maximum bending moment of semi-rigid beams under an applied member load has been considered for the variation of the rotational stiffnesses of end connections. The minimum value of the maximum moments which can be achieved by adjusting connection stiffness was presented and proved. He demonstrated that the cross-sectional member sizes based on this minimum value of the maximum moment will correspond to the leastweight solution for any values of connection stiffness.

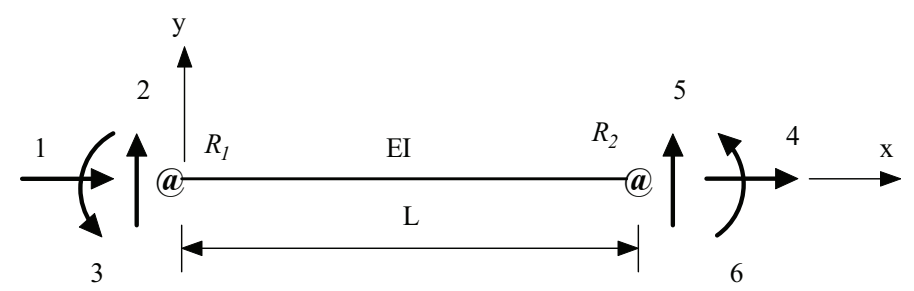

Fig. 1. Semi-rigid member

The end-fixity factor $r_{q}$ defines the stiffness of the beam-tocolumn connection in terms of the beam moment of inertia:

$$
r_{q}=\frac{1}{1+\frac{3 E I_{z}}{S_{q} L}}, \ldots \ldots(q=1,2)
$$

where $S_{q}$ is the end-connection spring stiffness, and $E I_{z} / L$ is the flexural stiffness of the attached member. For pinned connections, the rotational stiffness of the connection tends to zero and the value of the end-fixity factor is equal to zero as well. For rigid connections, the end-fixity factor is equal to $\left(r_{q}=1\right)$, and in case of a more realistic design, the semi-rigid connection results in a value between 1 and zero. The elastic stiffness matrix of a member $i$ with two semi-rigid end-connections having stiffness modulus $S_{q}(q=1,2)$ can be represented by the following stiffness matrix which is modified by a semi-rigid correction matrix:

$$
\mathbf{K}_{i}=\mathbf{K}_{S i}+\mathbf{K}_{C i}
$$

where $\mathbf{K}_{i}$ is the stiffness matrix of member $i$ with semi-rigid end-connections. The matrices $\mathbf{K}_{S i}$ and $\mathbf{K}_{C i}$ have the following forms:

$$
\mathbf{K}_{S i}=\left[\begin{array}{cccccc}
\frac{E A}{L} & 0 & 0 & -\frac{E A}{L} & 0 & 0 \\
0 & \frac{12 E I}{L^{3}} & \frac{6 E I}{L^{2}} & 0 & -\frac{12 E I}{L^{3}} & \frac{6 E I}{L^{2}} \\
& & \frac{4 E I}{L} & 0 & -\frac{6 E I}{L^{2}} & \frac{2 E I}{L} \\
& & & \frac{E A}{L} & 0 & 0 \\
& S Y M & & & \frac{12 E I}{L^{3}} & -\frac{6 E I}{L^{2}} \\
& & & & & \frac{4 E I}{L}
\end{array}\right]
$$




$$
\mathbf{K}_{C i}=
$$$$
\left[\begin{array}{cccccc}
1 & 0 & 0 & 0 & 0 & 0 \\
0 & \frac{4 r_{2}-2 r_{1}+r_{1} r_{2}}{4-r_{1} r_{2}} & \frac{2 L r_{1}\left(1-r_{2}\right)}{4-r_{1} r_{2}} & 0 & 0 & 0 \\
0 & \frac{6\left(r_{1}-r_{2}\right)}{L\left(4-r_{1} r_{2}\right)} & \frac{3 r_{1}\left(2-r_{2}\right)}{4-r_{1} r_{2}} & 0 & 0 & 0 \\
0 & 0 & 0 & 1 & 0 & 0 \\
0 & 0 & 0 & 0 & \frac{4 r_{1}-2 r_{2}+r_{1} r_{2}}{4-r_{1} r_{2}} & \frac{2 L r_{2}\left(1-r_{1}\right)}{4-r_{1} r_{2}} \\
0 & 0 & 0 & 0 & \frac{6\left(r_{1}-r_{2}\right)}{L\left(4-r_{1} r_{2}\right)} & \frac{3 r_{2}\left(2-r_{1}\right)}{4-r_{1} r_{2}}
\end{array}\right]
$$

where $E$ is Young's modulus, and $L, A, I$ are the length, crosssectional area, and moment of inertia of the member, respectively. The end-fixity factors $r_{1}$ and $r_{2}$ are defined by Eq. 2

The semi-rigid frames are more flexible than rigid steel frames. Therefore, in this study a stability analysis is required. The structural design constraints defined in the following subsections are extended by a structural stability analysis as well.

\subsection{Definition of the Discrete Design Problem}

The least weight design problem of frame structures with semi-rigid connections, considering only flexural behaviour, under applied loads can be defined as a discrete optimization problem in terms of the member sections, $A_{i}$ and in terms of the rotational stiffnesses of end connections, $S_{q}$. The design variables $A_{i}$ are selected from a discrete set of the predetermined $A_{i} \in B=\left\{B^{1}, B^{2}, \ldots, B^{N}\right\}$ cross-sectional areas of column elements, $A_{j} \in C\left\{C^{1}, C^{2}, \ldots, C^{N}\right\}$ cross-sectional areas of beam elements such that minimize the total weight, while $S_{q}$ rotational stiffnesses of end connections are changing in between a given equidistance range of $S_{q} \in S=\left\{S^{1}, S^{2}, \ldots, S^{E}\right\}$ values.

The objective function is

$$
\begin{gathered}
W\left(A_{i}, A_{j}\right) \rightarrow \min !, \\
i=1,2, \ldots, n \quad j=1,2, \ldots, m
\end{gathered}
$$

where $n$ is the number of column and $m$ is the number of beam elements, $q$ is the number of joints, $N$ is the number of cross sectional catalogue values for columns, $M$ is the number of cross sectional catalogue values for beam elements, and $E$ is the number of rotational stiffness value series.

The discrete minimal weight design is subjected to size, displacement, and stress constraints. In order to satisfy the design constraints listed above, we have to determine the displacements and internal force distribution of the framed structure in terms of member cross sections and connection stiffness of joint springs. The structural model and related formulas are concerned in several papers. The detailed description of the theoretical background could be found in book of Chan and Chui [1].

In this study, for structural analysis, the ANSYS Release 9.0 finite element program is applied. The structural model is formulated as a combination of $3 \mathrm{D}$ quadratic beam elements and linear torsional springs. The frame is defined in $x$ and $y$ plane. Therefore, $u_{x}$ and $u_{y}$ displacements, $\theta_{z}$ rotation, $F_{x}$ and $F_{y}$ member forces, and $M_{z}$ bending moment will be considered in the $3 \mathrm{D}$ coordinate system.

\subsection{Displacement Constraints}

The displacement constraints are

$$
u_{k}=\bar{u}_{k}<0, \quad k=1,2, \ldots, p
$$

where $u_{k}$ is the actual displacement value of the beam or column elements, $\bar{u}_{k}$ is its upper bound and $p$ is the number of restricted displacements.

\subsection{Bending and Axial Tension Constraints of the Columns and Beams}

Constraints for normal stresses are computed from the maximal value of bending moments and from the related normal forces or from the maximal value of axial forces and related bending moments.

$$
\frac{N}{f_{y} A}+\frac{M_{z}}{f_{y} W_{z}} \leq 1
$$

where $N$ is the actual axial force of the beam $\left(F_{x}\right)$ or column $\left(F_{y}\right)$ elements, $M_{z}$ is the bending moment, and $f_{y}$ is the yield stress, modified by the partial safety factor.

\subsection{Bending and Axial Compression Constraints of the Columns and Beams}

The frames are defined in the $x, y$, and $z$ global co-ordinate system where $z$ is the bending axis. The frame members are loaded by bending and axial forces. Therefore, the overall flexural and torsional buckling constraints are formulated according to Eurocode 3. We have to satisfy the following buckling constraints about the axis $z$ :

$$
\frac{N}{\chi_{z} f_{y} A}+k_{z} \frac{M_{z}}{\chi_{L T} f_{y} W_{z}} \leq 1,
$$

where $\chi_{z}$ is the overall buckling factor for the axis $z, \chi_{T}$ is the lateral-torsional buckling factor, $k_{z}$ is a modification factor in terms of the axial force effect.

The overall buckling factor $\chi_{z}$ for the axis $\mathrm{z}$ is

$$
\chi_{z}=\frac{1}{\phi_{z}+\sqrt{\phi_{z}^{2}-\lambda_{z}^{2}}}
$$

where

$$
\begin{gathered}
\phi_{z}=0.5\left[1+\alpha_{z}\left(\bar{\lambda}_{z}-0.2\right)+\bar{\lambda}_{z}^{2}\right], \\
\alpha_{z}=\left\{\begin{array}{lll}
0.21 & & h_{1} / b_{1}>1.2 \\
& \text { if } & \\
0.34 & & h_{1} / b_{1} \leq 1.2
\end{array} .\right.
\end{gathered}
$$

The slenderness ratio of the column is

$$
\bar{\lambda}_{z}=\frac{2 H}{r_{z} \lambda_{E}},
$$

and the slenderness ratio of the beam is

$$
\bar{\lambda}_{z}=\frac{1.3 L}{r_{z} \lambda_{E}} .
$$


where

$$
\lambda_{E}=\pi \sqrt{\frac{E}{f}} \ldots \quad r_{z}=\sqrt{\frac{I_{z}}{A}} .
$$

The lateral-torsional buckling factor $\chi_{T}$ is

$$
\chi_{T}=\frac{1}{\phi_{T}+\sqrt{\phi_{T}^{2}-\bar{\lambda}_{T}^{2}}},
$$

where

$$
\phi_{T}=0.5\left[1+\alpha_{T}\left(\bar{\lambda}_{T}-0.2\right)+\bar{\lambda}_{T}^{2}\right]
$$

and

$$
\alpha_{T}=\left\{\begin{array}{lll}
0.49 & & h_{1} / b_{1}>2 \\
& \text { if } & \\
0.34 & & h_{1} / b_{1} \leq 2
\end{array} .\right.
$$

The relative lateral-torsional factor is computed from the following formula:

$$
\bar{\lambda}_{T}=\sqrt{\frac{W_{z} f}{M_{c r}}},
$$

where $M_{c r}$ in case of columns is replaced by

$$
M_{c r}=11.132 \pi^{2} E \frac{I_{x}}{H} \sqrt{\frac{I_{\omega}}{I_{x}}+\frac{H^{2} G I_{t}}{\pi^{2} E I_{x}}},
$$

and in case of beams by

$$
M_{c r}=11.132 \pi^{2} E \frac{I_{y}}{L} \sqrt{\frac{I_{\omega}}{I_{y}}+\frac{L^{2} G I_{t}}{\pi^{2} E I_{y}}} .
$$

The $k_{z}$ factor is computed from the following formula replaced by the above defined variables:

$$
k_{z}=0.9\left[1+0.6 \bar{\lambda}_{z} \frac{N}{\chi_{z} f A}\right] .
$$

The buckling constraints about the $x$ axis for the column and about the $y$ axis for the beam elements are as follows:

$$
\frac{N}{\chi_{n} f_{y} A} \leq 1
$$

where $N$ is the actual axial force of the beam $\left(F_{x}\right)$ or column $\left(F_{y}\right)$ elements, $\chi_{n}$ is the overall buckling factor related to the $x$ axis for the column and about the $y$ axis for the beam elements.

The overall buckling factor $\chi_{n}$ for the axis $n=x$ of beam elements and $n=y$ for the column elements is

$$
\chi_{n}=\frac{1}{\phi_{n}+\sqrt{\phi_{n}^{2}-\lambda_{n}^{2}}},
$$

where

$$
\begin{gathered}
\phi_{n}=0.5\left[1+\alpha_{n}\left(\bar{\lambda}_{n}-0.2\right)+\bar{\lambda}_{n}^{2}\right], \\
\alpha_{n}=\left\{\begin{array}{lll}
0.21 & h_{1} / b_{1}>1.2 \\
049 & \text { if } & \\
& & h_{1} / b_{1} \leq 1.2
\end{array}\right.
\end{gathered}
$$

The slenderness ratio of the column is

$$
\bar{\lambda}_{y}=\frac{2 H}{r_{y} \lambda_{E}}
$$

and the slenderness ratio of the beam is

$$
\bar{\lambda}_{x}=\frac{1,3 L}{r_{x} \lambda_{E}}
$$

\section{The Optimization Procedure}

\subsection{The Applied Genetic Algorithm}

The genetic algorithm (GA) is an efficient and widely applied global search procedure based on a stochastic approach. All of the recently applied genetic algorithms for structural optimization have demonstrated that genetic algorithms can be powerful design tools (see e.g. [2, 3, 8], and [9]).

The crossover operation creates variations in the solution population by producing new solution strings that consist of parts taken from selected parent solution strings. The mutation operation introduces random changes in the solution population. In GA, the mutation operation can be beneficial in reintroducing diversity in a population. In this study, a pair of parent solutions is randomly selected, with a higher probability of selection being ascribed to superior solutions.

The two parents are combined using a crossover scheme that attempts to merge the strings representing them in a suitable fashion to produce an offspring solution. Offspring can also be modified by some random mutation perturbation. The algorithm selects the fittest solution of the current solution set, i.e. those with the best objective function values. Each pair of strings reproduces two new strings using a crossover process and then dies.

\subsection{The Steps of the Applied Algorithm}

Generations $=500$

PopulationSize $=500$

SwapProbability $=0.1$

MutationProbability $=0.1$

CrossoverProbability $=0.5$

Call ProblemDefinition

For Agent $=1$ to PopulationSize

Call RandomAgentGeneration (Agent)

Call PathFollowingMethod

Call BestFeasibleSolutionUpdate

Next Agent

For Generation $=1$ to Generations

Call PopulationOrderingByFitness (PopulationSize)

Call FittestParentPairSelection (CrossoverProbability)

Call Crossover (SwapProbability)

For Each Child: Call Mutation (MutationProbability)

Call PathFollowingMethod

Call BestFeasibleSolutionUpdate

\section{Next Generation}

\section{Numerical Examples}

The effects of semi-rigid connections are observed to the optimal design of steel frames. Two examples of planar frames are studied here. In this paper, a simple-bay frame (shown in Fig. 2) and a two-bay frame were considered where the objective function is the minimal weight (volume) of the structure subjected to the sizing, displacement, and stress constraints including the member buckling as well. The design variables are discrete vari- 
ables of the cross section of beam and column members. According to the structural symmetry requirements, symmetrical members are grouped into the same variables.

Tab. 1. Catalogue values of beam section types

\begin{tabular}{lrrrrrrrrr}
\hline $\begin{array}{l}\text { Section } \\
\text { type }\end{array}$ & $\begin{array}{r}h \\
{[\mathrm{~cm}]}\end{array}$ & $\begin{array}{r}b \\
{[\mathrm{~cm}]}\end{array}$ & $\begin{array}{r}t_{w} \\
{[\mathrm{~cm}]}\end{array}$ & $\begin{array}{r}t_{f} \\
{[\mathrm{~cm}]}\end{array}$ & $\begin{array}{r}A \\
{[\mathrm{~cm} 2]}\end{array}$ & $\begin{array}{r}I_{t} \\
{[\mathrm{~cm} 4]}\end{array}$ & $\begin{array}{r}I_{z} \\
{[\mathrm{~cm} 4]}\end{array}$ & $\begin{array}{r}I_{y} \\
{[\mathrm{~cm} 4]}\end{array}$ & $\begin{array}{r}I_{\omega} \\
{[\mathrm{cm}]}\end{array}$ \\
\hline IPE 80 & 8 & 4.6 & 0.4 & 0.5 & 7.64 & 0.7 & 80.1 & 8.5 & 119 \\
IPE 100 & 10 & 5.5 & 0.4 & 0.6 & 10.32 & 1.2 & 171 & 15.9 & 354 \\
IPE 120 & 12 & 6.4 & 0.4 & 0.6 & 13.21 & 1.7 & 317.8 & 27.7 & 894 \\
IPE 140 & 14 & 7.3 & 0.5 & 0.7 & 16.43 & 2.5 & 541.2 & 44.9 & 1989 \\
IPE 160 & 16 & 8.2 & 0.5 & 0.7 & 20.09 & 3.6 & 869.3 & 68.3 & 3977 \\
IPE 180 & 18 & 9.1 & 0.5 & 0.8 & 23.95 & 4.8 & 1317 & 100.9 & 7459 \\
IPE 200 & 20 & 10.0 & 0.6 & 0.9 & 28.48 & 7.0 & 1943.2 & 142.4 & 13053 \\
IPE 220 & 22 & 11.0 & 0.6 & 0.9 & 33.37 & 9.1 & 2771.8 & 204.9 & 22762 \\
IPE 240 & 24 & 12.0 & 0.6 & 1.0 & 39.12 & 12.9 & 3891.6 & 283.6 & 37575 \\
IPE 270 & 27 & 13.5 & 0.7 & 1.0 & 45.95 & 15.9 & 5789.8 & 419.9 & 70849 \\
IPE 300 & 30 & 15.0 & 0.7 & 1.1 & 53.81 & 20.1 & 8356.1 & 603.8 & 126333 \\
IPE 330 & 33 & 16.0 & 0.8 & 1.1 & 62.61 & 28.1 & 11770 & 788.1 & 199877 \\
IPE 360 & 36 & 17.0 & 0.8 & 1.3 & 72.73 & 37.3 & 16270 & 1043.5 & 314645 \\
IPE 400 & 40 & 18.0 & 0.9 & 1.3 & 84.46 & 51.1 & 23130 & 1317.8 & 492147 \\
IPE 450 & 45 & 19.0 & 0.9 & 1.5 & 98.82 & 66.9 & 33740 & 1675.9 & 794245 \\
IPE 500 & 50 & 20.0 & 1.0 & 1.6 & 115.52 & 89.3 & 48200 & 2141.7 & 125425 \\
IPE 550 & 55 & 21.0 & 1.1 & 1.7 & 134.42 & 123.2 & 67120 & 2667.6 & 189315 \\
IPE 600 & 60 & 22.0 & 1.2 & 1.9 & 155.98 & 165.4 & 92080 & 3387.3 & 285858 \\
\hline & & & & & & & & &
\end{tabular}

The applied material is given according to the European Standard prEN (Fe E 510) steel with a modulus of elasticity of 210 $000 \mathrm{MPa}$ and a yield stress of $355 \mathrm{MPa}$. The Poisson factor is 0.3 , and the material density is $7850 \mathrm{~kg} / \mathrm{m} 3$. The cross sections are selected from the European section profiles. In the presented example the beam and column profiles are distinguished, and the cross sections have been selected from the catalogue of Table 1, and Table 2. The applied loads are $p=5 \mathrm{kN} / \mathrm{m}$, and $P=50 \mathrm{kN}$, according to the Fig. 2

In this study, for structural analysis and for the optimal design problem, the ANSYS Release 9.0 finite element program was applied. The structural model is formulated as a combination of $3 \mathrm{D}$ quadratic beam elements and linear torsional springs. The frame is defined in $\mathrm{x}$, and $\mathrm{y}$ plane. The design constraints are formulated in $3 \mathrm{D}$ coordinate system using formulas (6)-27).

Beam-to-column connections are varying from ideallypinned to fully-rigid behaviour. The changes of the rotational stiffness of beam-to-column connections play a relevant role in the optimal design problem while the structural response is changing as well. In order to expose this effect to the optimal design, the connection stiffness ratio $\left(S_{q} L / E I_{z}\right)$ related to the beam element and the end-fixity factor is applied which was introduced and defined by $\mathrm{Xu}[11,12]$ first time. The end-fixity factors $r_{1}$ and $r_{2}$ are defined by Eq. (1).

For pinned connections, the rotational stiffness of the connection tends to zero and the value of the end-fixity factor is equal to zero as well. For rigid connections, the end-fixity factor is equal to $\left(r_{q}=1\right)$, and in case of a more realistic design, the semi-rigid connection results in a value between 1 and
Tab. 2. Catalogue values of column section types

\begin{tabular}{|c|c|c|c|c|c|c|c|c|c|}
\hline $\begin{array}{l}\text { Section } \\
\text { type }\end{array}$ & $\begin{array}{r}h \\
{[\mathrm{~cm}]}\end{array}$ & $\begin{array}{r}b \\
{[\mathrm{~cm}]}\end{array}$ & $\begin{array}{r}t_{w} \\
{[\mathrm{~cm}]}\end{array}$ & $\begin{array}{r}t_{f} \\
{[\mathrm{~cm}]}\end{array}$ & $\begin{array}{r}A \\
{[\mathrm{~cm} 2]}\end{array}$ & $\begin{array}{r}I_{t} \\
{[\mathrm{~cm} 4]}\end{array}$ & $\begin{array}{r}I_{z} \\
{[\mathrm{~cm} 4]}\end{array}$ & $\begin{array}{r}I_{y} \\
{[\mathrm{~cm} 4]}\end{array}$ & $\begin{array}{r}I_{\omega} \\
{[\mathrm{cm} 6]}\end{array}$ \\
\hline $\mathrm{HE} 120 \mathrm{~A}$ & 11.4 & 12.0 & 0.5 & 0.8 & 25.34 & 6.0 & 606.2 & 230.9 & 6486 \\
\hline $\mathrm{E} 120 \mathrm{AA}$ & 10.9 & 12.0 & 0.4 & 0.5 & 18.55 & 2.8 & 413.4 & 158.8 & 4253 \\
\hline E120 B & 12.0 & 12.0 & 0.6 & 1.1 & 34.01 & 13.8 & 864.4 & 317.5 & 9431 \\
\hline E120 M & 14.0 & 12.6 & 1.3 & 2.1 & 66.41 & 91.7 & 2017.6 & 702.8 & 24880 \\
\hline $\mathrm{E} 140 \mathrm{~A}$ & 13.3 & 14.0 & 0.5 & 0.9 & 31.42 & 8.1 & 1033.1 & 389.3 & 15086 \\
\hline $\mathrm{E} 140 \mathrm{AA}$ & 12.8 & 14.0 & 0.4 & 0.6 & 23.02 & 3.5 & 719.5 & 274.8 & 10226 \\
\hline E140 B & 14.0 & 14.0 & 0.7 & 1.2 & 42.96 & 20.1 & 1509.2 & 549.7 & 22514 \\
\hline E140 M & 16.0 & 14.6 & 1.3 & 2.2 & 80.56 & 120.0 & 3291.4 & 1144.3 & 54482 \\
\hline E160 A & 15.2 & 16.0 & 0.6 & 0.9 & 38.77 & 12.2 & 1673 & 615.6 & 31469 \\
\hline E160 AA & 14.8 & 16.0 & 0.4 & 0.7 & 30.36 & 6.3 & 1282.9 & 478.7 & 23794 \\
\hline $\mathrm{E} 160 \mathrm{~B}$ & 16.0 & 16.0 & 0.8 & 1.3 & 54.25 & 31.2 & 2492 & 889.2 & 48038 \\
\hline$E 160 \mathrm{M}$ & 18.0 & 16.6 & 1.4 & 2.3 & 97.05 & 162.4 & 5098.3 & 1758.8 & 108380 \\
\hline $\mathrm{HE} 180 \mathrm{~A}$ & 17.1 & 18.0 & 0.6 & 1.0 & 45.25 & 14.8 & 2510.3 & 924.6 & 60289 \\
\hline E180 AA & 16.7 & 18.0 & 0.5 & 0.8 & 36.53 & 8.3 & 1966.9 & 73 & 46427 \\
\hline HE180 B & 18.0 & 18.0 & 0.9 & 1.4 & 65.25 & 42.2 & 3831.1 & 1362.8 & 93887 \\
\hline $\mathrm{E} 180 \mathrm{M}$ & 20.0 & 18.6 & 1.5 & 2.4 & 113.25 & 203.3 & 7483.1 & 2580.1 & 199805 \\
\hline E200 A & 19.0 & 20.0 & 0.6 & 1.0 & 53.83 & 21.0 & 3692.2 & 1335.5 & 108176 \\
\hline HE200 AA & 18.6 & 20.0 & 0.5 & 0.8 & 44.13 & 12.7 & 2944.3 & 1068.5 & 84635 \\
\hline $\mathrm{E} 200 \mathrm{~B}$ & 20.0 & 20.0 & 0.9 & 1.5 & 78.08 & 59.3 & 5696.2 & 2003.4 & 171413 \\
\hline E200 M & 22.0 & 20.6 & 1.5 & 2.5 & 131.28 & 259.4 & 10640 & 3651.2 & 347093 \\
\hline E220 A & 21.0 & 22.0 & 0.7 & 1.1 & 64.34 & 28.5 & 5409.7 & 1954.6 & 193506 \\
\hline $\mathrm{HE} 220 \mathrm{AA}$ & 20.5 & 22.0 & 0.6 & 0.9 & 51.46 & 15.9 & 4170.2 & 1510.5 & 145809 \\
\hline E220 B & 22.0 & 22.0 & 1.0 & 1.6 & 91.04 & 76.6 & 8091 & 2843.3 & 295813 \\
\hline HE220 M & 24.0 & 22.6 & 1.6 & 2.6 & 149.44 & 315.3 & 14600 & 5012.1 & 573830 \\
\hline E240 A & 23.0 & 24.0 & 0.8 & 1.2 & 76.84 & 41.6 & 7763.2 & 2768.8 & 328962 \\
\hline $\mathrm{HE} 240 \mathrm{AA}$ & 22.4 & 24.0 & 0.6 & 0.9 & 60.38 & 23.0 & 5835.2 & 2077.0 & 240028 \\
\hline E240 B & 24.0 & 24.0 & 1.0 & 1.7 & 105.99 & 102.7 & 11260 & 3922.7 & 487675 \\
\hline IE240 M & 27.0 & 24.8 & 1.8 & 3.2 & 199.59 & 627.9 & 24290 & 8152.6 & 1154493 \\
\hline E260 A & 25.0 & 26.0 & 0.8 & 1.3 & 86.82 & 52.4 & 10450 & 3667.6 & 517183 \\
\hline HE260 AA & 24.4 & 26.0 & 0.6 & 1.0 & 68.97 & 30.3 & 7980.6 & 2788.0 & 383288 \\
\hline AE260 B & 26.0 & 26.0 & 1.0 & 1.8 & 118.44 & 123.8 & 14920 & 5134.5 & 754853 \\
\hline HE260 M & 29.0 & 26.8 & 1.8 & 3.3 & 219.64 & 719.0 & 31310 & 10450 & 1732251 \\
\hline HE280 A & 27.0 & 28.0 & 0.8 & 1.3 & 97.26 & 62.1 & 13670 & 4762.6 & 786419 \\
\hline HE280 AA & 26.4 & 28.0 & 0.7 & 1.0 & 78.02 & 36.2 & 10560 & 3664.2 & 591005 \\
\hline HE280 B & 28.0 & 28.0 & 1.1 & 1.8 & 131.36 & 143.7 & 19270 & 6594.5 & 1131686 \\
\hline HE280 M & 31.0 & 28.8 & 1.9 & 3.3 & 240.16 & 807.3 & 39550 & 13160.0 & 2524384 \\
\hline
\end{tabular}

zero. In this examples, the rotational stiffnesses of end connections are changing in between a given equidistance range of $S_{q} \in S=\{1 \mathrm{E} 4 ; 5 \mathrm{E} 4 ; 1 \mathrm{E} 5 ;$ 5E5; 1E6; 5E6;1E7; 5E7 $\}$ values.

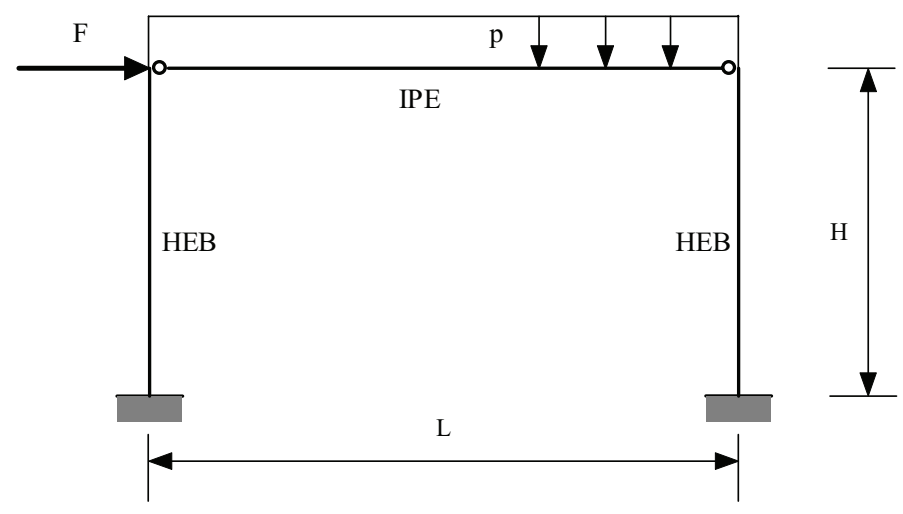

Fig. 2. Semi rigid single-bay frame 
Tab. 3. Results of the single-bay frame under symmetric loading. (*Note: WZB1 and WZC1 - section modulus of the beam and column of optimal solution, TVOL - the total volume of the optimal solution, MAXMZB - the maximal bending moment of the beam element, MAXROTZ - the maximal rotation.)

Tab. 4. Results of the single-bay frame under unsymmetrical loading (Note: WZB1 and WZC1 - section modulus of the beam and column of optimal solution, TVOL - the total volume of the optimal solution, MAXFXB - the maximal axial force of the beam element, MAXFYCA and MAXFYCB - the maximal axial forces of the column elements, MAXMZB the maximal bending moment of the beam element, MAXMZCA and MAXMZCB - the maximal bending moment of the column elements, MAXROTZ the maximal rotation.)

Tab. 5. Results of the two-bay frame - displacements and buckling constraints (Note: MINUX, MAXUX, MINUY, and MAXUY indicate the minimal and maximal values of displacements. The buckling constraints (BUCK) for beams and columns are considered as well.)

\begin{tabular}{lrrrrrrrr}
\hline$r_{q}$ & 0.00955 & 0.04599 & 0.08794 & 0.42209 & 0.59362 & 0.92146 & 0.95912 & 0.99155 \\
$S_{q}$ & 10000 & 50000 & $1.0 \mathrm{E}+05$ & $5.0 \mathrm{E}+05$ & $1.0 \mathrm{E}+06$ & $5.0 \mathrm{E}+06$ & $1.0 \mathrm{E}+07$ & $5.0 \mathrm{E}+07$ \\
WZB1* & $1.46 \mathrm{E}-04$ & $1.46 \mathrm{E}-04$ & $1.46 \mathrm{E}-04$ & $1.09 \mathrm{E}-04$ & $1.09 \mathrm{E}-04$ & $7.73 \mathrm{E}-05$ & $7.73 \mathrm{E}-05$ & $7.73 \mathrm{E}-05$ \\
WZC1* & $7.59 \mathrm{E}-05$ & $7.59 \mathrm{E}-05$ & $7.59 \mathrm{E}-05$ & $7.59 \mathrm{E}-05$ & $7.59 \mathrm{E}-05$ & $7.59 \mathrm{E}-05$ & $7.59 \mathrm{E}-05$ & $7.59 \mathrm{E}-05$ \\
TVOL* & $3.4 \mathrm{E}-02$ & $3.4 \mathrm{E}-02$ & $3.4 \mathrm{E}-02$ & $3.1 \mathrm{E}-02$ & $3.1 \mathrm{E}-02$ & $2.8 \mathrm{E}-02$ & $2.8 \mathrm{E}-02$ & $2.8 \mathrm{E}-02$ \\
MAXMZB* & 39621 & 38281 & 36922 & 29091 & 26615 & 20904 & 20511 & 20185 \\
MAXROTZ* & $3.84 \mathrm{E}-02$ & $3.64 \mathrm{E}-02$ & $3.44 \mathrm{E}-02$ & $3.63 \mathrm{E}-02$ & $3.18 \mathrm{E}-02$ & $3.47 \mathrm{E}-02$ & $3.36 \mathrm{E}-02$ & $3.27 \mathrm{E}-02$ \\
\hline
\end{tabular}

\begin{tabular}{|c|c|c|c|c|c|c|c|c|}
\hline$r_{q}$ & 4.6E-02 & 8.79E-02 & 0.42209 & 0.39521 & 0.76567 & 0.86728 & 0.9703 & 0.98493 \\
\hline$S_{q}$ & 50000 & $1.0 \mathrm{E}+05$ & $5.0 \mathrm{E}+05$ & $1.0 \mathrm{E}+06$ & $5.0 \mathrm{E}+06$ & $1.0 \mathrm{E}+07$ & $5.0 \mathrm{E}+07$ & $1.0 \mathrm{E}+08$ \\
\hline WZB1 & 1.46E-04 & $0.15 \mathrm{E}-03$ & $0.108 \mathrm{E}-03$ & 0.19E-03 & $0.19 \mathrm{E}-03$ & $0.19 E-03$ & 0.19E-03 & $0.19 \mathrm{E}-03$ \\
\hline WZC1 & 3.1E-04 & $0.31 \mathrm{E}-03$ & $0.31 \mathrm{E}-03$ & $0.22 \mathrm{E}-03$ & $0.17 \mathrm{E}-03$ & $0.17 \mathrm{E}-03$ & $0.17 \mathrm{E}-03$ & $0.17 \mathrm{E}-03$ \\
\hline TVOL & $6.26 \mathrm{E}-02$ & 6.26E-02 & 5.95E-02 & $5.4 \mathrm{E}-02$ & 4.7E-02 & 4.7E-02 & 4.7E-02 & 4.7E-02 \\
\hline MAXFXB & 25622 & 26197 & 29914 & 29276 & 31226 & 31648 & 32029 & 32080 \\
\hline MAXFYCA & 19542 & 19136 & 17232 & 14179 & 10750 & 10275 & 9857.5 & 9802.8 \\
\hline MAXFYCB* & 20458 & 20864 & 22768 & 25821 & 29250 & 29725 & 30143 & 30197 \\
\hline MAXMZB* & 38207 & 36671 & 27323 & 34774 & 53671 & 56700 & 9387 & 59741 \\
\hline MAXMZCA & 87721 & 85562 & 74531 & 62811 & 47259 & 44964 & 42941 & 42675 \\
\hline MAXMZCB & 88615 & 87523 & 83329 & 70621 & 58741 & 57232 & 55919 & 55748 \\
\hline rotation & $0.354 \mathrm{E}-01$ & $0.32 \mathrm{E}-01$ & $0.287 \mathrm{E}-01$ & $0.14 \mathrm{E}-01$ & $0.12 \mathrm{E}-01$ & $0.11 \mathrm{E}-01$ & $0.11 \mathrm{E}-01$ & $0.11 \mathrm{E}-01$ \\
\hline SET & SET 133 & SET 133 & SET 133 & SET 108 & SET 83 & SET 108 & SET 108 & SET 108 \\
\hline DESIGN & feasible & feasible & feasible & feasible & ible & feasible & feasible & teasıble \\
\hline MINUX & $.26 \mathrm{E}-03$ & $.117 \mathrm{E}-02$ & $.210 \mathrm{E}-02$ & $.706 \mathrm{E}-02$ & $.101 \mathrm{E}-01$ & $.891 \mathrm{E}-02$ & $.889 \mathrm{E}-02$ & $.883 E-02$ \\
\hline MAXUX & $.26 \mathrm{E}-03$ & $.117 \mathrm{E}-02$ & $.210 \mathrm{E}-02$ & $.706 \mathrm{E}-02$ & $.101 \mathrm{E}-01$ & $.891 \mathrm{E}-02$ & .889E-02 & $.883 E-02$ \\
\hline MINUY & $.96 \mathrm{E}-01$ & $.922 \mathrm{E}-01$ & $.878 \mathrm{E}-01$ & $.914 \mathrm{E}-01$ & .10174 & $.531 \mathrm{E}-01$ & $.489 \mathrm{E}-01$ & $.454 \mathrm{E}-01$ \\
\hline MAXUY & $.79 \mathrm{E}-30$ & $.789 E-30$ & $.789 E-30$ & $.789 E-30$ & $.789 E-30$ & $.789 \mathrm{E}-30$ & $.789 \mathrm{E}-30$ & $.789 E-30$ \\
\hline BUCKC11 & .19039 & .24322 & .29628 & .57611 & .74660 & .66249 & .65814 & .65193 \\
\hline BUCKC12 & .35076 & .35096 & .35149 & .36038 & .36810 & .38620 & .39033 & .39421 \\
\hline BUCKC13 & .18813 & .23303 & .27808 & .51526 & .65961 & .58675 & .58274 & .57717 \\
\hline BUCKB11 & .65705 & .63801 & .61745 & .65869 & .82926 & .70973 & .75255 & .79129 \\
\hline BUCKB12 & .65705 & .63801 & .61745 & .65869 & .77971 & .47189 & .45500 & .44019 \\
\hline TVOL (OBJ) & ) $.61 \mathrm{E}-01$ & $.606 \mathrm{E}-01$ & $.606 \mathrm{E}-01$ & $.544 \mathrm{E}-01$ & $.485 \mathrm{E}-01$ & $.544 \mathrm{E}-01$ & $.544 \mathrm{E}-01$ & $.544 \mathrm{E}-01$ \\
\hline
\end{tabular}

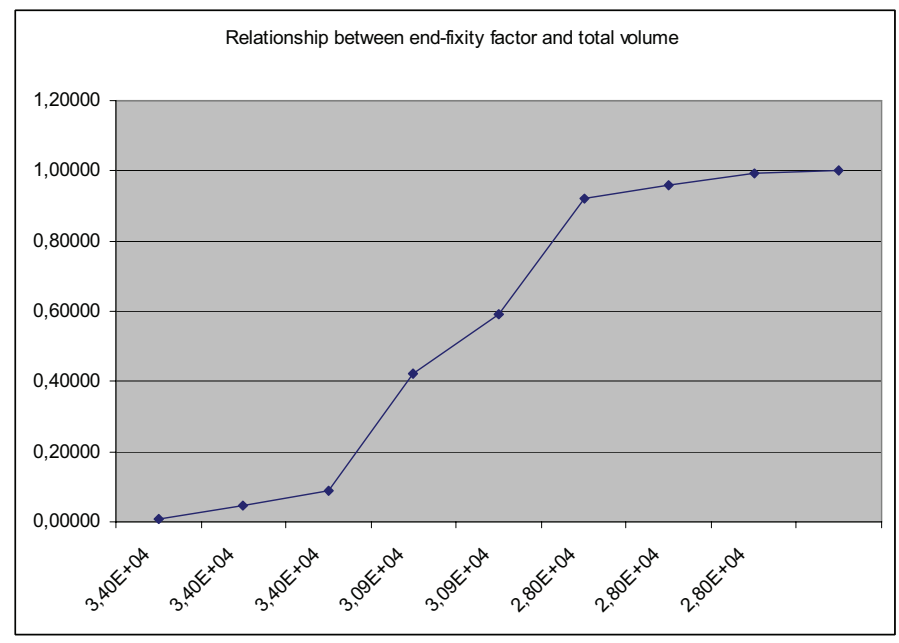

Fig. 3. Results of the single-bay frame under symmetric loading

\section{Conclusions}

In this paper, a genetic algorithm was applied for discrete minimal weight design of steel planar frames with semi-rigid beam-to-column connections. The frame elements are constructed from a predetermined range of section profiles. Two different catalogue values were determined for beam and col-

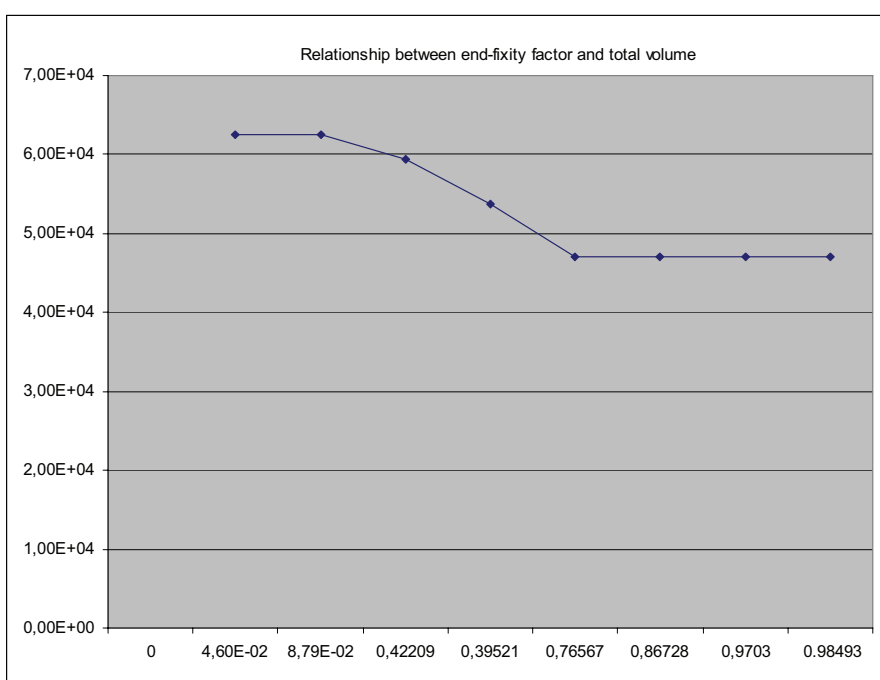

Fig. 4. Results of the single-bay frame - under unsymmetrical loading

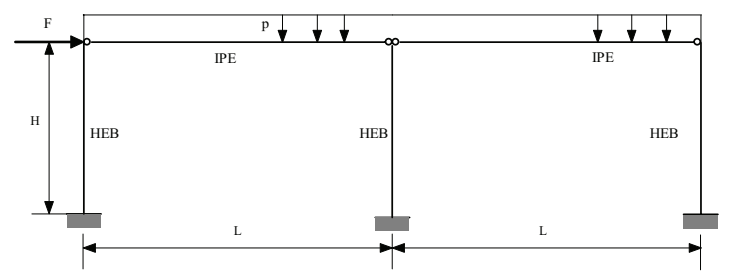

Fig. 5. Semi-rigid two-bay frame 


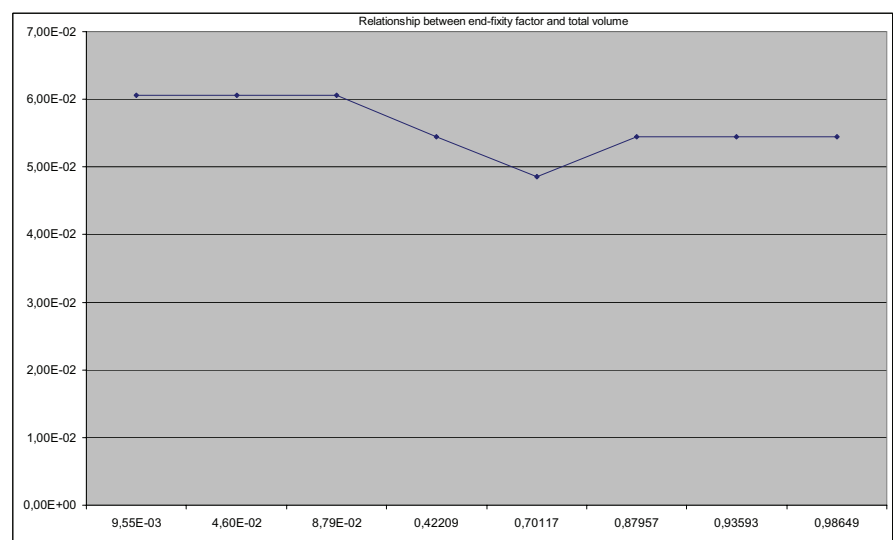

Fig. 6. Results of the two-bay frame

umn sections. In this study, both the structural analysis and the optimal design problem were solved, using ANSYS Release 9.0 finite element program.

The purpose of this study was to determine the effect of the rotational stiffness of beam-to-column connection in the optimal design while the structural response was changing. The results obtained for single-bay and two-bay frame structures are shown in Tables 3, 4, 5. The relationship between the optimal volume and the end-fixity factor is presented in Figs. 3, 4, 6, The optimal solutions highly depend on the structural geometry and on the loading conditions. For discrete optimal design of two-bay frame we obtained better solution in case of semi-rigid joints than in case of rigid or pinned connections.

\section{References}

1 Chan SL, Chui PPT, Non-linear Static and Cyclic Analysis of Steel Frames with Semi-rigid Connections, Elsevier, UK, 2000.

2 Csébfalvi A, A Genetic Algorithm for Discrete Optimization of Space Trusses with Plastic Collapse Constrains, Proceedings of The Seventh International Conference on Computational Structures Technology, 7-9 September 2004, Lisbon, Portugal, Civil-Comp Press, Stirling, Scotland, 2004, pp. 651-652.

3 Goldberg DE, Samtani MP, Engineering Optimization via Genetic Algorithms, 9th Conference on Electronic Computation, ASCE, New York, 1986, pp. $471-482$.

4 Eurocode 3 (EC3): Annex J: Joints in building frames, Commission of the European Communities, 1993. ENV 1993-1-1, CEN.

5 Eurocode 3 (EC3): Design of steel structures, part 1.1: General rules and rules for buildings, European Committee for Standardization, 1998. ENV 1993-1-1, CEN.

6 Hayalioglu MS, Degertekin SO, Design of Non-linear Steel Frames for Stress and Displacement Constraints with Semi-rigid Connection via Genetic Optimization, Struct. Multidisc. Optim. 27 (2004), 259-271.

7 Jármai K, Farkas J, Uys P, Optimum Design and Cost Calculation of a Simple Frame with Welded or Bolted Joints, Welding in the World 48 (2004), no. 1-2, 42-49.

8 Pezeshk S, Camp CV, Chen D, Design of non-linear framed structures using Genetic Optimization, Journal of Structural Engineering 126 (2000), no. 3, 382-388.

9 Rajeev S, Krishnamoorty CS, Discrete Optimization of Structures Using Genetic Algorithms, Journal of Structural Engineering 118 (1992), no. 5, 1233-1250.

10 Xu L, Grierson DE, Computer Automated Design of Semi-rigid Steel Frameworks, Journal of Structural Engineering 119 (1993), 1740-1760.

11 Xu L., Optimal Design of Steel Frameworks with Semi-rigid Connections, Ph.D. Thesis, 1994.

$12 \mathrm{Xu} \mathbf{L}$, On the Minimum-maximum Bending Moment and the Least-weight Design of Semi-rigid Beams, Struct. Multidisc. Optim. 21 (2001), 316-321. 